\title{
Carbon dioxide sorption on EDTA modified halloysite
}

\author{
Patrycja Waszczuk ${ }^{1}$, Marcin Lutynski, 2,a, Miguel A. Gonzalez Gonzalez², Adam Smolinski ${ }^{1}$, and Natalia \\ Howaniec $^{1}$ \\ ${ }^{1}$ Głowny Instytut Gornictwa, Plac Gwarkow 40 - 166 Katowice, Poland \\ ${ }^{2}$ Politechnika SI aska, ul Akademicka 2, 41-100 Gliwice, Poland
}

\begin{abstract}
In this paper the sorption study of $\mathrm{CO}_{2}$ on EDTA surface modified halloysite was conducted. In the paper chemical modification of halloysite from the Dunino deposit (Poland) and its influence on sorption of $\mathrm{CO}_{2}$ are presented. A halloysite samples were washed with waterEDTA 1\% solution, centrifuged to separate liquid and impurities and dried. The samples were tested for the sorption capacity using a manometric method with pressure up to $3 \mathrm{MPa}$. A Langmuir adsorption model was fitted to the data. The results showed that EDTA had a limited effect on the increase of sorption potential at low pressure and the samples exhibited similar results to that ones treated solely with the water solution.
\end{abstract}

\section{Introduction}

Emission reduction and improving carbon capture technologies are currently the important issues in a carbon constrained world. It is especially desirable in countries where the main power source are fossil fuels, in particular coal. It is necessary to clean exhaust gases, which contain also $\mathrm{SO}_{2}, \mathrm{NO}_{\mathrm{X}}$ and other, mainly acidic, oxides.

A sorption study was conducted on a modified halloysite to verify modification of surface properties. Halloysite is an aluminosilicate clay mineral, consisting of aluminium, silica and hydrogen, with formula $\mathrm{Al}_{2} \mathrm{Si}_{2} \mathrm{O}_{5}(\mathrm{OH})_{4}$. It naturally occurs with montmorillonite and kaolinite with small additions of other clay minerals, often contaminated with ilmenite. Other impurities in the raw halloysite material are iron and titanium oxides. In the past, halloysite was used as a petroleum cracking catalyst, also known for its sorption properties. It also can be used in nanocomposites as a filler [1-5].

It is suggested that modification of halloysite can improve sorption selectivity and/or increase sorption capacity of $\mathrm{CO}_{2}$. The purpose of this research was to find modification of halloysite, which helps to improve selectivity of the sorbent. Typical sorbent reactivation can be divided into chemical and thermal treatment methods. In the case of chemical treatment the surface of sorbent is modified by chemical impregnation which can significantly increase the sorption capacity. As a method of modification surface impregnation with EDTA was chosen. EDTA is a ethylenediaminetetraacetic acid, widely known for its properties as a chelating agent and limescale dissolvent. It has the ability to complex, among others, heavy metal ions, but the most important is its ability to sequest $\mathrm{Fe}^{3+}$ ion.

${ }^{a}$ Corresponding author: Marcin.Lutynski@polsl.pl 
A halloysite is strongly polluted with an ilmenite, which decreases its sorption properties. It was assumed that the EDTA supported the purification process and modified the surface at the same time. There is only one paper which shows EDTA action on halloysite [6]. The paper contains description of the devastating effects of acid on structure of halloysite immediately after mixing both substances. But after a longer time (90 days) a recrystallisation and expansion in diameter of nanotubes was observed.

\section{Materials and methods}

\subsection{Materials}

For the purpose of the study, raw halloysite from the Dunino deposit in western Poland was chosen. The halloysite Dunino deposit is located in the Lower Silesia and contains over 10 million tons of a homogeneous raw material mined using an open pit method. Halloysite extracted from this deposit is a product of basalt weathering.

The method of activated sample preparation involved immersing the sample in impregnating solution of $1 \%$ EDTA for an hour, shaking for 30 minutes and centrifuging aqueous at 2500 RPM for 10 minutes. The other raw sample of halloysite was prepared in the same manner with the exception that instead of EDTA and water mixture, pure demineralized water was used.

Consequently, the samples were dried in the oven at $105^{\circ} \mathrm{C}$ for 2 to 24 hours, depending on the collected volume of mixtures. Before placing the samples in the cell of the sorption apparatus the samples were vacuumed.

The halloysite sample modified with EDTA was marked as a hall-EDTA and the sample prepared with demineralized water was marked as a hall-water. For the purpose of comparison we have also performed tests on raw halloysite, neither water immersion nor centrifuging, acquired straight from the deposit. The raw halloysite was crushed, sieved to the fraction below $0.1 \mathrm{~mm}$ and dried for 1 hour. This sample was marked as a hall-raw.

\subsection{Methods}

Sorption experiments were performed using the manometric technique with the custom made sample cells and setup. The process of adsorption removes sorbate gas molecules from the free gas phase, and thus results in a decrease of the gas pressure within the experimental system. The most fundamental operational procedure to quantify gas adsorption is the Gibbs approach, where the amount of adsorbed gas $\left(n_{\text {adsorbed }}\right)$ is defined as the difference between the total amount of gas $\left(n_{\text {total }}\right)$ present in the system and the amount occupying the void volume $\left(V_{\text {void }}\right)$, i.e. the volume not occupied by the solid sample. This latter quantity is calculated from the molar concentration $\left(c_{\text {gas }}\right)$ in the gas phase which is obtained from an equation of the gas state under corresponding pressure and temperature conditions:

$$
n_{\text {sorbed }}=n_{\text {total }}-c_{\text {gas }} \cdot V_{\text {void }}=n_{\text {total }}-c_{\text {gas }}\left(V_{\text {sample cell }}-V_{\text {sample }}\right) .
$$

Prior to the start the helium experiment the void volume of the sample cell $\left(V_{\text {void }}\right)$ is measured. For this purpose an inert gas (helium) is used. The density of gas is calculated with the McCarthy equation of state for helium. Multiplication of the void volume by the density of the gas $\left(V_{\text {void }} \rho^{\mathrm{CO} 2}(T, P)\right)$ gives the "non-sorption" reference mass, i.e. the amount of gas that would be accommodated in the measuring cell for no sorption. The excess sorption mass is the difference between the gas mass that is transferred into the measuring cell up to a given pressure step and the non-sorption reference mass:

$$
m_{\text {excess }}^{\mathrm{CO}_{2}}=m_{\text {transferred }}^{\mathrm{CO}_{2}}-V_{\text {void }} \cdot \rho^{\mathrm{CO}_{2}}(T, P) .
$$

Sorption measurement is done in consecutive steps and the gas mass transferred from the reference cell into the sample cell at each step $(N)$ can be calculated with the following formula: 


$$
m_{\text {transferred }}^{\mathrm{CO}_{2}}=\sum_{i=1}^{N} V_{\text {ref }} \cdot\left(\rho_{i}^{f, \mathrm{CO}_{2}}-\rho_{i}^{e, \mathrm{CO}_{2}}\right) .
$$

Superscripts in the equation i.e. $f, \mathrm{CO}_{2}$ and $e, \mathrm{CO}_{2}$ refer to the density of gas in the filling phase (when the reference cell is not connected with the sample cell) and equilibrium phase (when the reference cell is connected with the sample cell and the pressure is equilibrated), respectively. Densities are calculated with the use of high-accurate equations [7]. The schematic diagram of the manometric sorption methodology is presented in Figure 1.

The manometric setup used for the experiments consists of the sample and reference cells, valves, tubing, pressure transducers and temperature sensors (Fig. 2). The gas is injected into the setup by a pump and prior to start of the experiment the system is evacuated with the use of the vacuum pump. The pressure is monitored with the use of a pressure transducers. The pressure transducers are connected to the data acquisition system. The temperature is monitored with PT100 sensors which are connected to the multi-channel temperature data-logger, which communicates with the data acquisition system. The sample cells were designed and constructed at the Silesian University of Technology. Fittings and valves used in the setup are high pressure fittings made of stainless steel with $1 / 4$, tubing. Setup is immersed in pure water in custom made bath with electronic temperature stabilization of $0.1{ }^{\circ} \mathrm{C}$ [8].
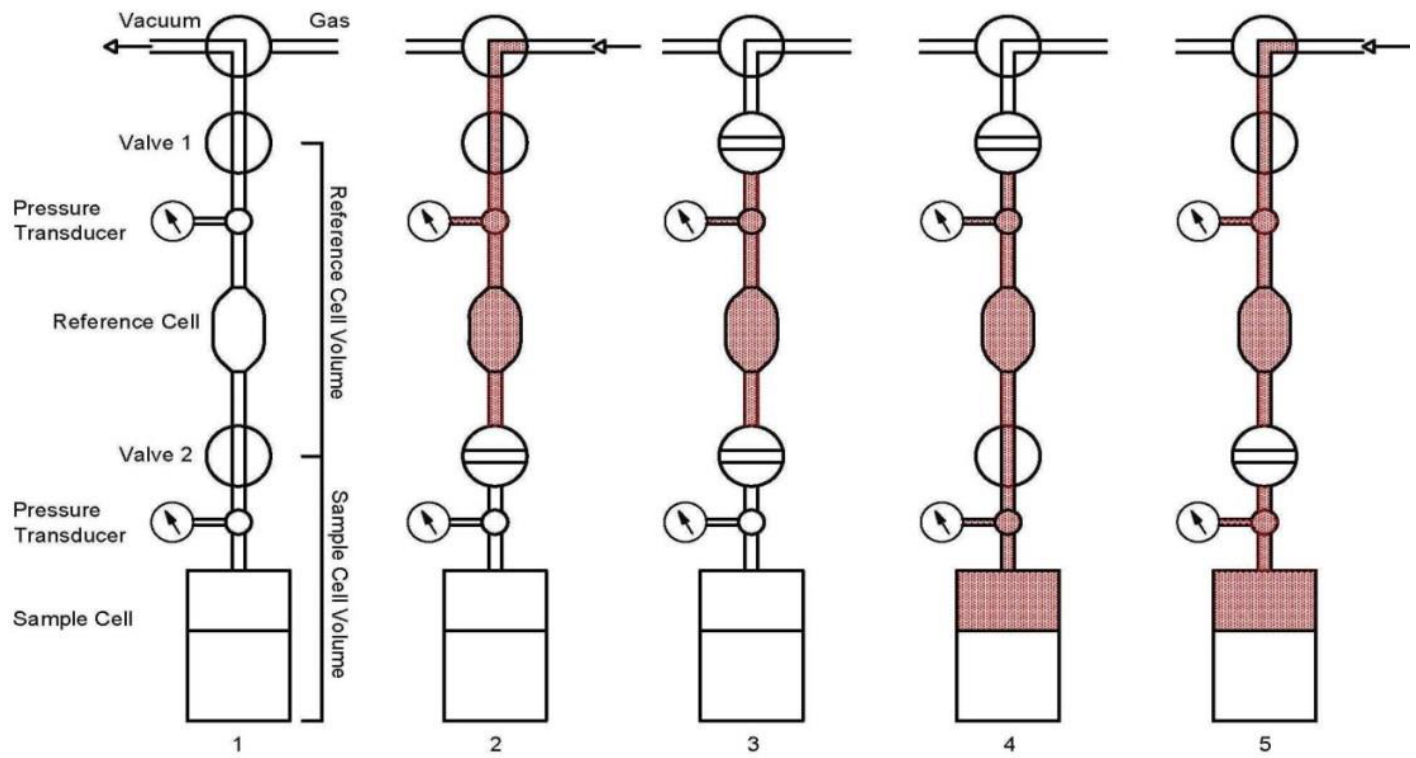

Figure 1. Schematic diagram of manometric sorption methodology, where each figure indicates each step: 1 evacuation of the system, 2 - filling of the reference cell, 3 - closure of the valve 1 and thermal equilibration, 4 valve 2 is opened and gas is transferred into the sample cell (start of the sorption process), 5 - when pressure equilibrium is reached, valve 2 is closed and refilling of the reference cell starts. 


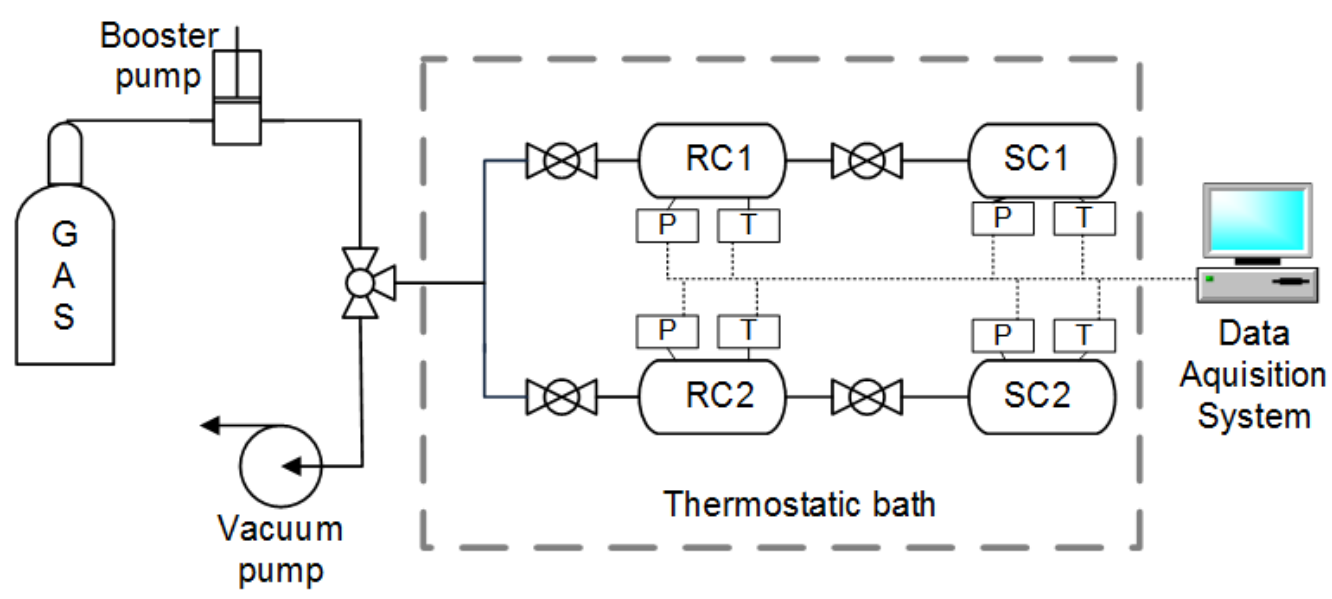

Figure 2. Scheme of high-pressure sorption manometric setup.

\section{Results and discussion}

An interesting phenomena occurred during sample preparation. After centrifuging the hall-EDTA and hall-water samples stratification occurred and the samples had different colours of separated liquid. Also sharper boundaries between layers of different densities could be seen (Fig. 3).

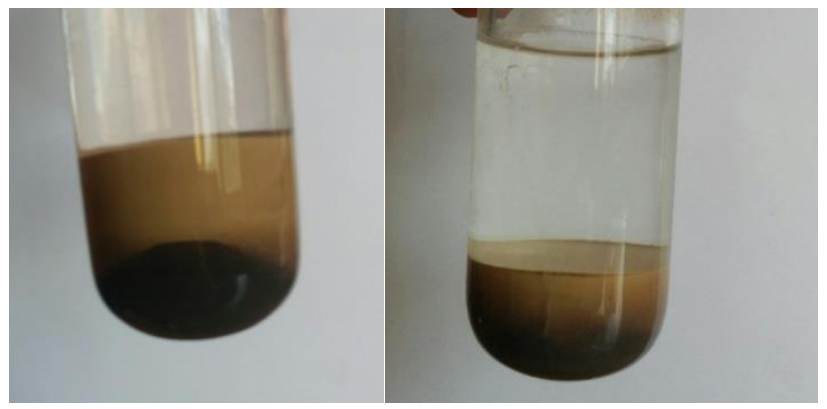

Figure 3. View of samples after separation in centrifuge: (left) with EDTA solution and (right) with demineralized water.

In order to acquire the hall-EDTA and hall-water samples for the experiments a "light" fraction was removed from the tube. The "dark" part of the mixture was probably iron and other metal oxides impurities. The results of sorption tests are presented in Fig. 4. Experiments were conducted at pressure of $3 \mathrm{MPa}$. The equilibrium time for each step was 1-2 hours. The experimental results were fitted with the Langmuir model and the calculated Langmuir constants are presented in Table 1. The results of experiments are also presented in Fig. 4. It was noticed that maximum adsorption was for the raw halloysite sample, next EDTA modified halloysite, and then halloysite washed with water.

The Langmuir model was calculated with the following equation:

$$
V=\frac{V_{L} \cdot P}{P_{L} \cdot P}
$$

where $P$ is pressure (MPa), $V_{L}$ is the Langmuir volume $(\mathrm{mmol} / \mathrm{g})$ and $P_{L}$ is the Langmuir pressure (MPa). 


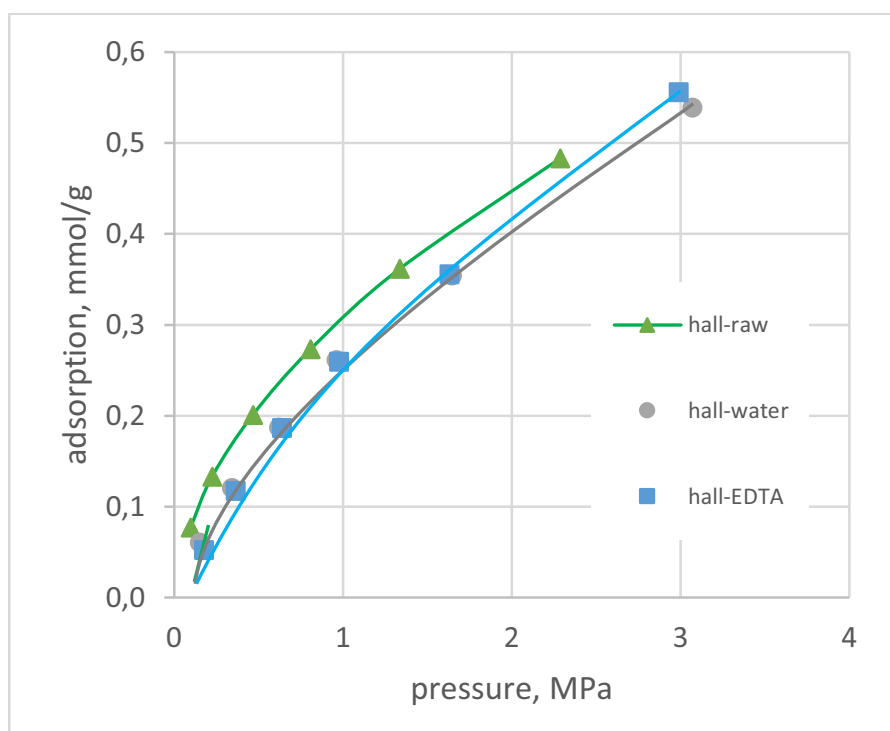

Figure 4. $\mathrm{CO}_{2}$ excess sorption isotherms on the hall-EDTA, hall-water and hall-raw samples at $45^{\circ} \mathrm{C}$.

Table 1. Calculated Langmuir constants for samples.

\begin{tabular}{|l|c|c|}
\hline Sample & $V_{L}, \mathrm{mmol} / \mathrm{g}$ & $P_{L}, \mathrm{MPa}$ \\
\hline Hall-EDTA & 1.256 & 3.841 \\
\hline Hall-water & 1.024 & 2.854 \\
\hline Hall-raw & 0.713 & 1.192 \\
\hline
\end{tabular}

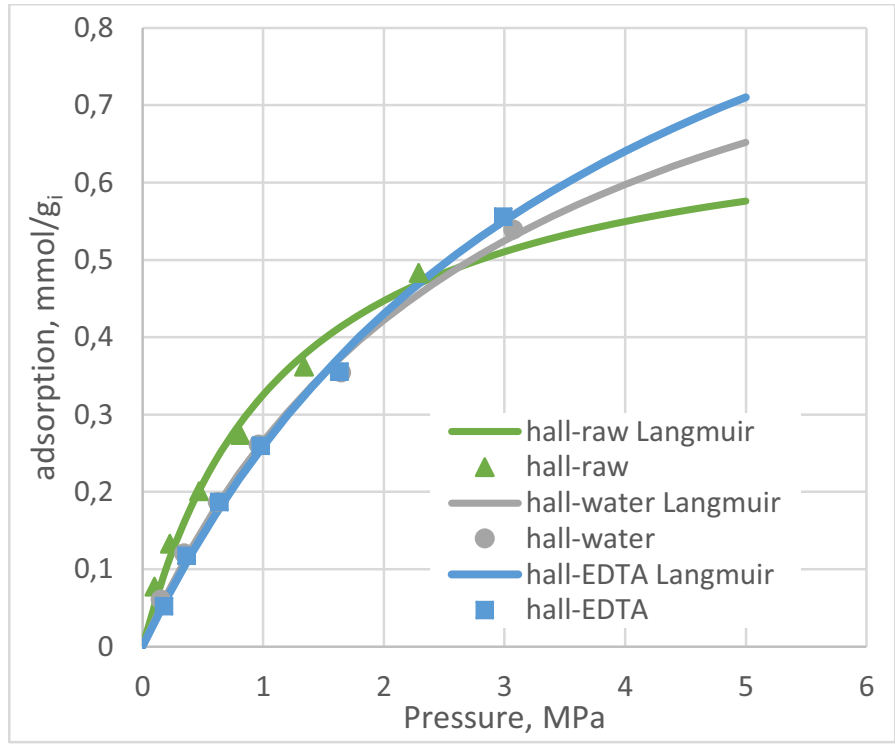

Figure 5. $\mathrm{CO}_{2}$ excess sorption isotherms on the hall-EDTA, hall-water and hall-raw samples at $45{ }^{\circ} \mathrm{C}$ fitted and extrapolated with the Langmuir model. 
Although the highest sorption capacity is visible in the hall-raw sample up to the pressure of $1 \mathrm{MPa}$ it reaches the plateau level faster than other samples. After applying the model it could be noticed that for higher pressure (above $3 \mathrm{MPa}$ ) sorption is the highest for the hall-EDTA sample. This is reflected in the calculated Langmuir constants, where $V_{L}$ has the highest value for the hall-EDTA sample (meaning the highest sorption capacity for infinite pressure). Lower $V_{L}$ values are for the hall-water and hall-raw samples, respectively.

\section{Conclusions}

It can be noticed, that addition of EDTA slightly improves halloysite sorption capacity. Probably it is not due to surface modification but rather enhances separation between halloysite and irony contamination in the presence of EDTA. EDTA rather large and branched molecules, which could occupy the pores being the centers of adsorption for gas. The gaseous phase probably is reluctant to sorption on the EDTA molecule.

A tendency to increase the sorption capacity is observed at pressure above $3 \mathrm{MPa}$ since the Langmuir volume for the hall-EDTA and hall-water samples is higher than for the hall-raw sample. It is not clear whether it is due to either the model equation or at higher pressure an unidentified phenomenon occurs impossible to explain based on the tests performed. A further research of sorption at $3 \mathrm{MPa}$ as well as the surface analysis of modified material is necessary to check if there is any difference between the modified and unmodified materials.

\section{References}

1. P. Yuan, P.D. Southon, Z. Liu, C.J. Kepert, Nanotechnology, 23, (2012)

2. P. Sakiewicz, R. Nowosielski, W. Pilarczyk, K. Gołombek, M. Lutynski, JAMME (2011)

3. K. Hedicke-Hochstotter, G.T. Lim, V. Altstadt, Compos. Sci. Technol., 69 (2009)

4. R. Kamble, M. Ghag, S. Gaikawad, B. Kumar Panda, J. Adv. Sci., 3, 2 (2012)

5. E. Joussein, S. Petit, C. Fialips, P. Vieillard, D. Righi, Clay Clays Miner., 54(4) (2006)

6. A. La Inglesia, E. Galan, Clay Clays Miner., (1975)

7. W. Wagner, R. Span, Int. J. Thermophysics, (1993)

8. M. Lutynski, Bulletin of the Polish Academy of Science, 62(1) (2014) 